\title{
Continuous Measurement of Atmospheric Ozone by an Automatic Photoelectric Method
}

\author{
Ralph Stair, Thomas C. Bagg, and Russell G. Johnston
}

\begin{abstract}
An automatic photoelectric instrument and method for the continuous measurement of the ozone in the earth's atmosphere at low altitudes are described. The method is physical rather than chemical in character and is based upon the optical absorption characteristics of ozone in the Hartley and Huggins ultraviolet bands. The instrument makes use of a lowpressure mercury arc, which is situated at a distance of 1,450 feet from the recording station that employs a 1P28 photomultiplier as a detector. The light beam is modulated, at 510 cycles per second, so that the output of the photomultiplier is fed into a tuned alternatingcurrent amplifier and amplified to the recorder level. By means of a Geneva mechanism, which changes the glass filters, the radiant energy from the lamp is separated into bands primarily at wavelengths $253.7,365.5$, and 405.0 millimicrons. From the ratios of the deflections for the different spectral regions it is possible to determine ozone concentration in the range from a few tenths of 1 part to many parts per 100 million.
\end{abstract}

\section{Introduction}

Although ozone is an important constituent of the atmosphere because of its protective effect in absorbing short-wave solar radiation, it is highly deleterious to rubber and related organic products. Because ozone is a highly oxidizing or catalytic agent, the presence of organic particles in the atmosphere, together with the effects of long-wave solar radiation and increased temperature at lower altitudes, results in the destruction of most of the ozone molecules below about 15 to $18 \mathrm{~km}$ under normal conditions of atmospheric circulation [1]. ${ }^{2} \quad$ As a result of the loss of ozone at low altitudes and a decrease in total pressure with altitude, the partial pressure of ozone near the earth's surface is only about one-tenth that of its maximum at an altitude of about $22 \mathrm{~km}$. Relative to the total number of molecules of air per unit volume, these figures become about 2 and 600 parts per 100 million, respectively.

Because ozone of significant amount is normally produced only at high altitudes in the stratosphere by short-wave ultraviolet solar radiation through a process of photochemical dissociation of the oxygen molecule, followed by recombination, any of the gas found at the earth's surface must have been transported there by some means [12]. Diffusion is slow and hence for the lower altitudes may be neglected. General large-scale air-mass movements associated with cyclonic and anticyclonic conditions, together with local air circulation resulting from thunderstorms and the like, must, therefore, be responsible for any ozone transportation at a rate sufficient to upset the static balance at the earth's surface. In fact, variations in the ozone concentration associated with air-mass movements are well known [13].

The primary purpose of this investigation has been to find a practical physical method for use in the routine measurement of the concentration of ozone

\footnotetext{
1 This work was sponsored by the Army Ordnance Department.

2 Figures in brackets refer to literature references at the end of this paper.
}

in the atmosphere at low altitudes, in particular at the surface of the earth. It may be that through such studies valuable information on air-mass movement or other weather phenomena may be obtained. An instrument for this purpose should prove especially valuable in the correlation of the deterioration of rubber products with ozone changes.

Rubber, when exposed to ozone, develops a type of cracking of the surface not produced by other elements or materials normally in the atmosphere [2]. These cracks develop much more rapidly when the rubber is cured under strain [3] or when it is under stress resulting from a bending or elongation of the sample. It has been found that in outdoor exposure of rubber the amount of cracking varies seasonally and with locality. The resulting cracking is sufficiently reproducible that it may be used as a rough quantitative measure of the amount of ozone by exposing a sample of specially prepared rubber [4] to the atmosphere under the tension produced simply by bending the sample. Although the results are greatly affected by temperature [5] the method has been found useful in rough quantitative determinations of ozone.

By employing the rubber-cracking method of ozone measurement, a survey at a number of cities in 1949 showed variations from a severity factor of 360 in Los Angeles and Denver to less than 30 in New York City and Conshohocken, Pa. [6]. These tests were in general agreement with rubber-deterioration experience for the localities involved. Nor is the local ozone concentration entirely dependent upon transportation of the gas from the stratosphere. Tests made in connection with the Los Angeles smog [7] indicate the formation of excessive amounts of ozone by photochemical action associated with the oxidization of hydrocarbons by nitrogen oxides present within the area.

In recent years interest in the deteriorating effect of ozone on rubber materials has increased greatly. The development of new synthetic elastomers having 
varying degrees of resistant properties to ozone also has contributed to an increased interest in this field. Although ozone is only one of several agents influencing the deterioration of rubber materials under the complex conditions of exposure to weather, it frequently proves to be the most severe [8]. Simple methods for the accurate measurement of its concentration are urgently needed.

Various chemical methods for the measurement of ozone have been suggested and set up. Most of them are elaborate, require close attention, and integrate over a relatively long interval of time. A method recently developed by Regener [1] has shortened the interval to about $30 \mathrm{~min}$, as well as making all the processes of the measurement automatic. In the past, physical measurements of ozone have been considered, but no real progress has been made in this direction, although the high optical absorption of ozone between 2,500 and 2,600 A lends itself ideally to the use of a physical (optical) instrument for this purpose. The present report deals with the development of such an instrument.

\section{Instruments and Methods}

The method chosen for investigation, as indicated above, is physical in character and is based on the optical absorption characteristics of ozone in the ultraviolet spectrum. Although ozone has several intense absorption bands at various wavelengths within the ultraviolet, visible, and infrared regions of the spectrum, the strongest is the Hartley band centered between 2,500 and 2,600 A. The optical density of ozone (designated absorption coefficient, $\alpha,[9,10])$ as obtained by $\mathrm{Ny}$ Tsi-Ze and Choong Shin-Piaw is depicted as a function of wavelength in figure 1. Although the absorption band is broad,

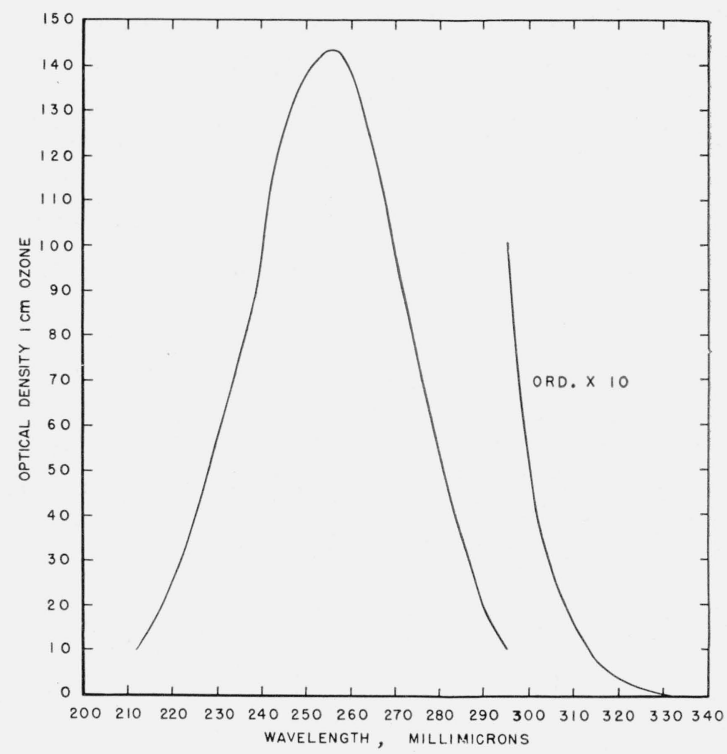

Figure 1. Optical density of ozone, from the data of Ny Tsi-Ze and Choong Shin-Piaw given in references [9] and [10].

it does not extend to wavelengths longer than about $3,400 \mathrm{~A}$, even for a thickness of $1 \mathrm{~cm}$ of ozone (normal temperature and pressure) which value is about 3 to 5 times the total in the earth's atmosphere at any time.

As ozone has a maximum of absorption in the spectral region of 2,500 to $2,600 \mathrm{~A}$ a source having high optical emission at $2,537 \mathrm{~A}$, such as a lowpressure mercury arc lamp, lends itself ideally to use in a physical setup. No other available light source has such ideal characteristics for this purpose.

TABLE 1. Method employed in the calculation of ozone values

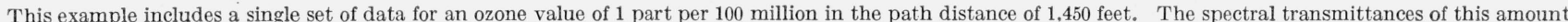

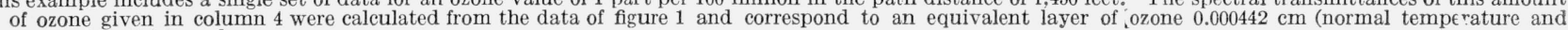
pressure) in thickness]

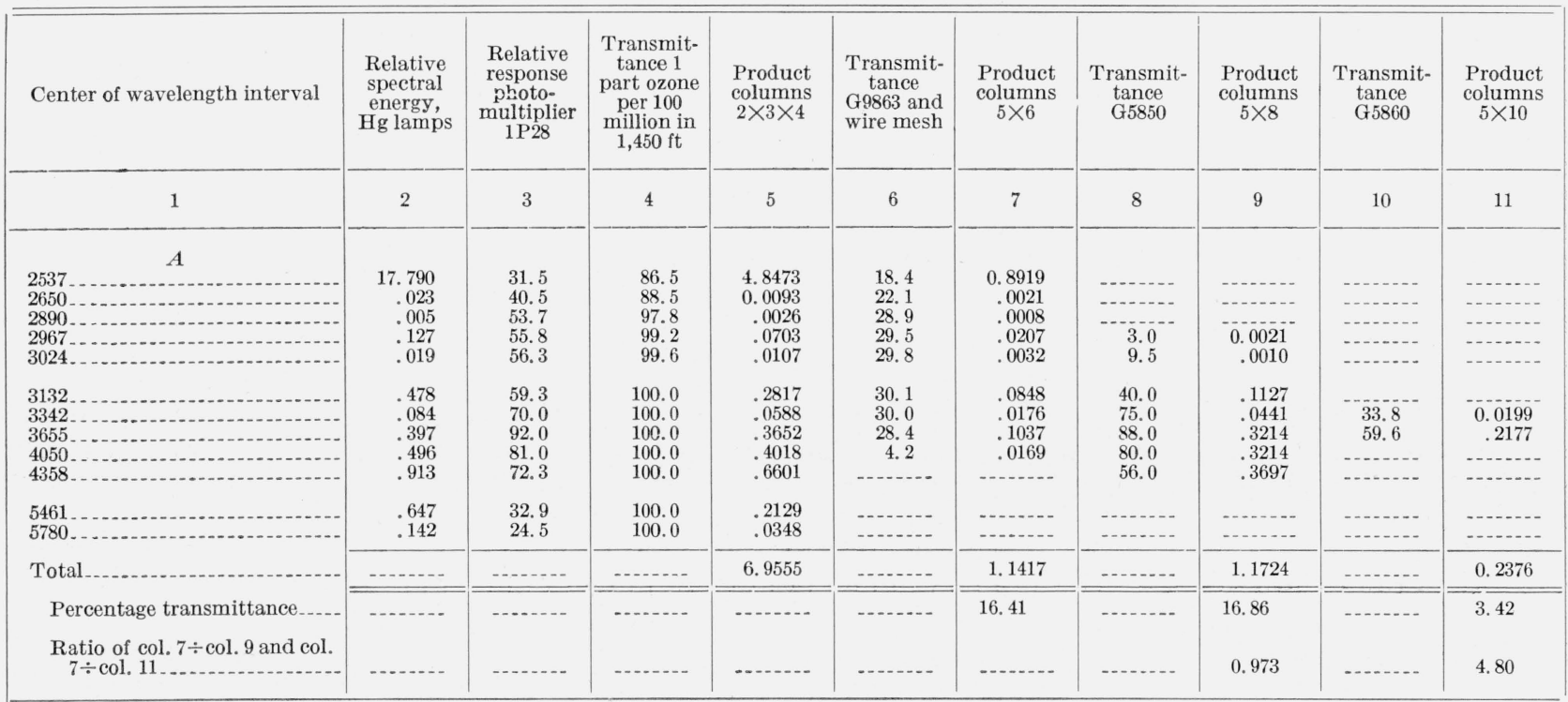


When the lamp is equipped with a glass tube that absorbs the $1,847-\mathrm{A}$ emission line, ${ }^{3}$ very little radiant energy is emitted at wavelengths below 3,650 A other than at 2,537 A. The spectral-energy distribution of such a source is given in table 1 .

For convenience of modulation by a sector disk [11], a source concentrated in space is preferred. However, as no such source is commercially available, a bank of five Westinghouse Sterilamps (nonozone type) was assembled, with a 2 -in. section of each tube (see fig. 2 for a block diagram of the setup) as the source of radiation. ${ }^{4}$ The radiant energy from the $2 \mathrm{in}$. section of these lamps is modulated by means of a rotating sector disk driven by a $1 / 3$-hp, 1,800-rpm synchronous motor. The disk has 17 openings, so that the light beam is modulated at $510 \mathrm{c} / \mathrm{s}$. One purpose of the modulated beam is to eliminate as far as possible the effect of other sources of light that might fall upon the photodetector. Other frequencies, in particular $120 \mathrm{c} / \mathrm{s}$, were considered but were discarded in favor of the 510 cy [11].

The light source is electrically modulated at 120 $\mathrm{c} / \mathrm{s}$ by the a-c line voltage. At first thought, it appeared that this would be ideal for the purpose. However, 60- and 120-cy electrical pickup and stray light modulated at the same frequencies ruled out the practical use of $120 \mathrm{c} / \mathrm{s}$. The electrical modulation of the light source at $120 \mathrm{c} / \mathrm{s}$ has been found not to interfere with the chopped modulation at $510 \mathrm{c} / \mathrm{s}$. Higher-frequency modulation would be preferred, except for the practical difficulties involved in the mechanical chopping of a beam of sufficient aperture to supply adequate radiant energy for the measurements.

At the detector station the modulated light beam is picked up by a 1P28 photomultiplier connected with a tuned amplifier and recorder. The special photometer unit contains a Geneva mechanism for automatically changing optical filters over the photomultiplier. A set of three Corning glass filters has been arranged on a disk, so that alternate readings are made at $2,537 \mathrm{~A}$ (principally), in the blue (including wavelengths $3,655,4,050$ and 4,358 $\mathrm{A}$ ), and at 3,655 A, (see fig. 3). Each filter is placed in front of the photomultiplier for 15 sec, after which the filter disk is rapidly moved to a new position for the next filter in the series. The fourth filter position carries an opaque shutter. Hence, during each minute a complete series of measurements is completed and recorded.

By means of a timing clock the source is automatically turned on about $30 \mathrm{~min}$ before a similar

\footnotetext{
3 Since ozone is created from free oxygen atoms, which are in turn created by photodissociation in the Schumann-Runge continuum, starting around 1,900 A the source will produce a large amount of ozone if the emission line 1,847 A is not removed. Such ozone production would greatly interfere with absorption measurements. In fact a small ozone concentration near the lamp results from 2,537 A riant energy [14]. This has negligible ffects unon the measurements. 2,537 A radiant energy [14]. This has negligible effects upon the measurements. ${ }^{4}$ No condensing lens or mirror was employed in this work. The light source was allowed to shine normally upon the detector. Although the resulting intensity was low, its constancy more than compensated for the reduced in tensity because of the refractive and reflective difficulties encountered in the use of a figured reflective mirror. As the source intensity and detector sensitivity were not limiting difficulties in this work, precaution was taken to eliminate a many optical problems as possible. As a matter of fact, the size of the light source could be diminished appreciably without encountering any grave difficulties.
}

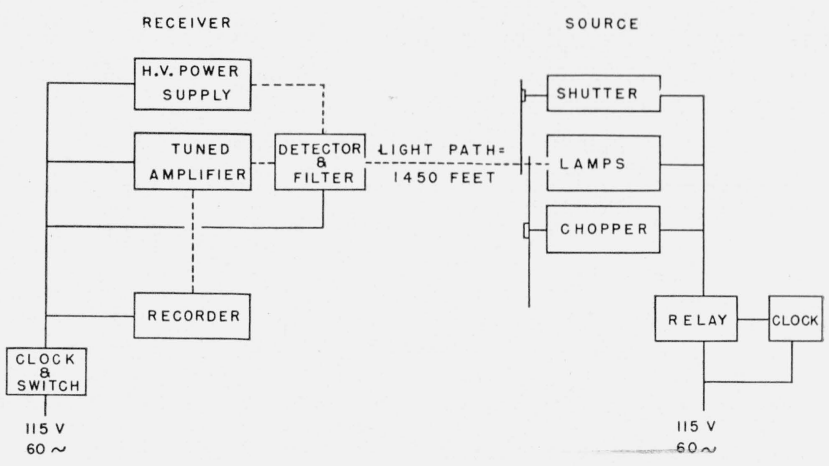

Figure 2. Block diagram of ozone meter.

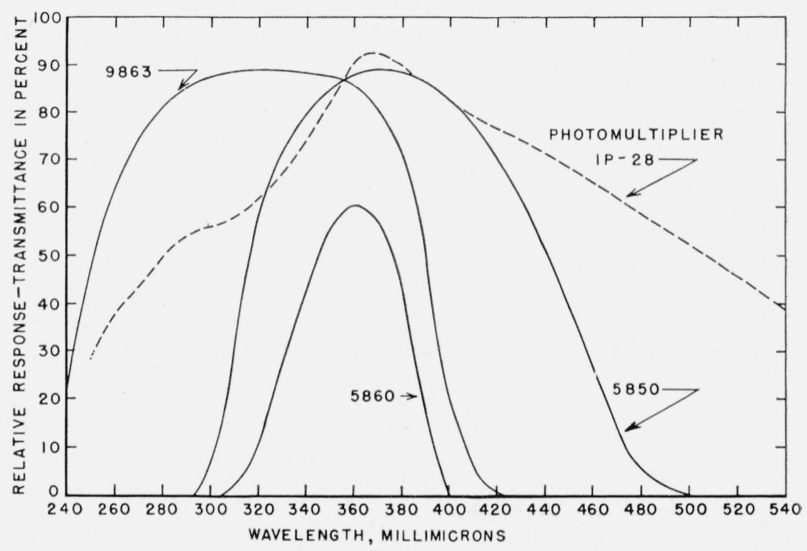

Figure 3. Transmittance curves for the Corning filters and the relative spectral response of the RCA 1P28 photomultiplier.

clock starts the receiving apparatus. Likewise, the same clocks turn off the equipment at a prearranged time each night. As all the components are controlled by timing clocks, the equipment requires no personal attention during the periods when it is in operation. Only daytime servicing and noting pertinent weather data, etc., are required.

The electric circuits for the 1P28 photomultiplier and for the tuned amplifier are displayed in figures 4 and 5. As the radiant energy transmitted through $1,450 \mathrm{ft}$ from 2 -in. sections of five Sterilamps is extremely low, the modulated source and the tunedcircuit amplifier were required in order to reduce the noise and to eliminate the zero drift resulting from the variable dark current in the photomultiplier. The photomultiplier was commonly operated at about $70 \mathrm{v}$ per anode, which resulted in a voltage amplification of the detected signal of about 100,000. Following this, a tuned a-c amplifier (with a voltage gain of several thousand) was employed to improve the signal to noise ratio and to obtain sufficient voltage for operating a standard strip recorder.

Because the photomultiplier is highly sensitive to changes of voltage, a carefully regulated power supply is essential for precision work. The power 


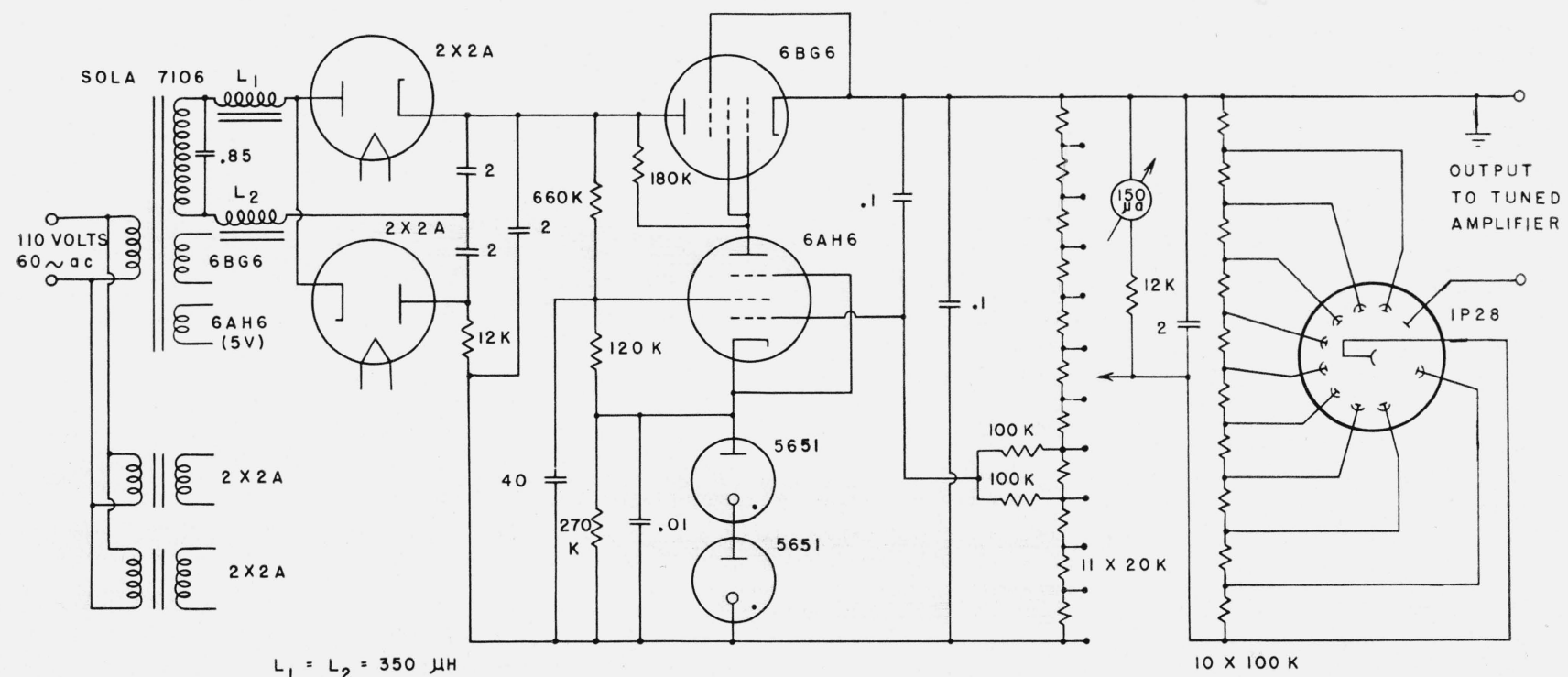

FIGURE 4. Electronic circuit employed in the photomultiplier unit.

Resistances in megohms and capacities in microfarads except as otherwise noted.

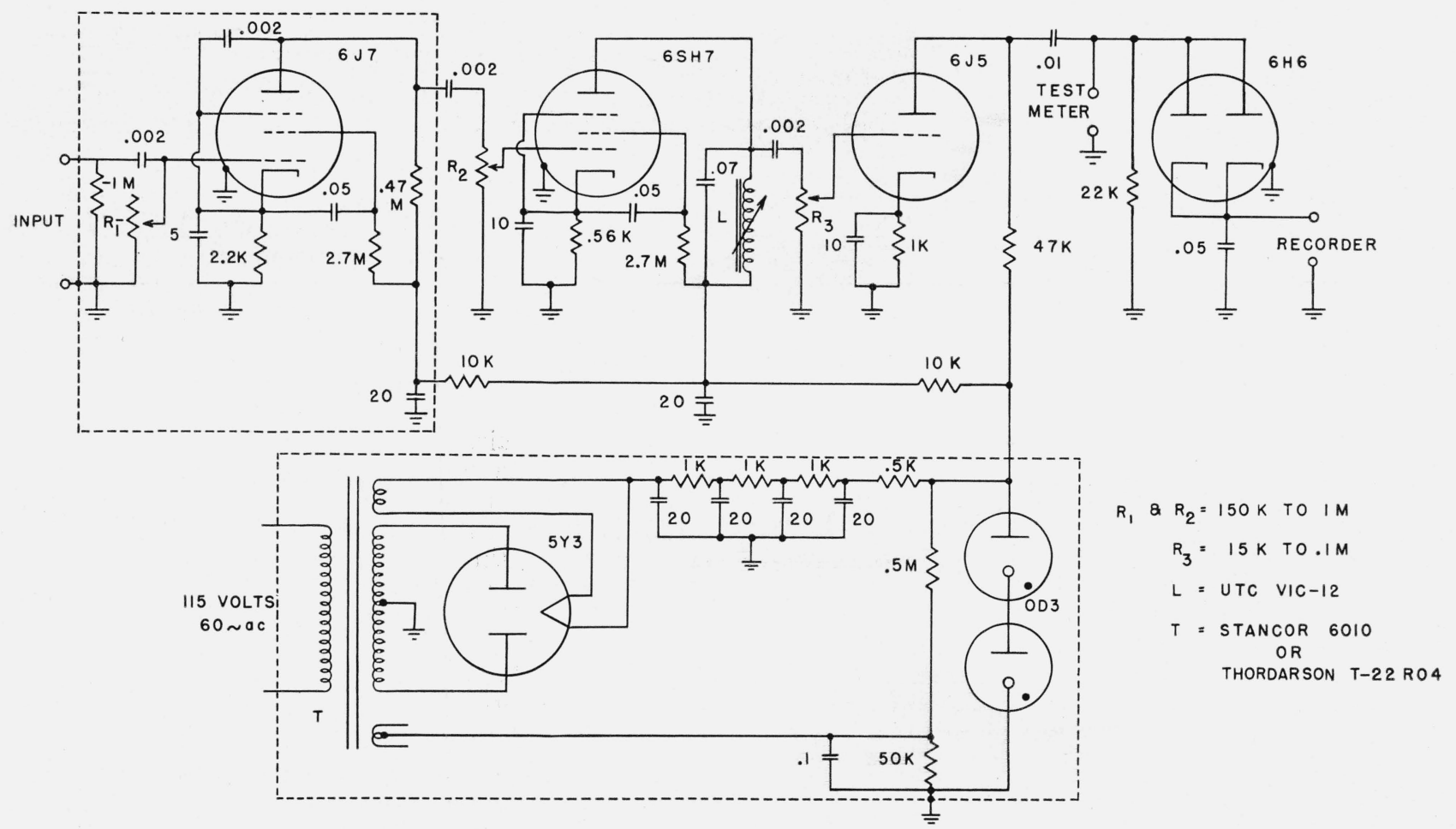

FIgURE 5. Electronic circuit employed in the 510-cycle-per-second tuned amplifier.

Resistance in megohms and capacities in microfarads except as otherwise noted. 
supply used (see fig. 4) contains many of the circuit elements commonly employed in conventional units, to keep the output voltage constant over a wide range of input voltage. As the electric load of the amplifier is relatively constant, little attention was given to regulatory devices to cover load variations.

The tuned amplifier (see fig. 5), peaked at $510 \mathrm{c} / \mathrm{s}$ has certain characteristics that may be noted. The input stage employs a 6J7 tube for producing a relatively flat gain at a high signal-to-noise ratio. But little shaping is introduced by the coupling and feedback elements in this circuit. The second stage, employing a $6 \mathrm{SH} 7$ tube, contains a tuned secondary consisting of a variable inductor shunted by a fixed low-loss condenser. This combination results in a pass band of about $75 \mathrm{cy}$. The amplifier is stable at all gain settings, yet has a sufficiently narrow pass band to reduce noise and power-line frequency interference to a relatively low level.

Amplifier gain is controlled by stepped resistor banks in each of the three stages. Ample shielding of the first stage, together with plate decoupling networks, reduces noise pickup and positive feedback to a minimum.

The output of the amplifier, after rectification by a $6 \mathrm{H} 6$ twin diode, is fed into a commercial potentiometer-type recorder. For purposes of test and adjustment, the a-c output of the amplifier may be read on a suitable vacuum-tube voltmeter. Thea-c voltage output is linear for all values below about 20 v. Recorded d-c values are slightly nonlinear as the result of contact potential within the $6 \mathrm{H} 6$ diode rectifier. However, this error becomes a secondorder effect as ratios only are employed in the reduction of the amount of ozone. If desired, any scale errors may be eliminated through an a-c voltage calibration of the $d-c$ recorder deflection. Usually close linearity has been obtained for all deflections above $1 \mathrm{v}$ when full recorder-scale deflection was set at $10-\mathrm{v}$ (alternating current) measured at the test-meter position.

The method employed in the evaluation of the amount of ozone in the $1,450-\mathrm{ft}$ path between the light source and the detecting system is illustrated by a sample calculation in table 1 , which gives all the steps in the determination of the filter-transmission factors corresponding to a concentration of 1 part of ozone in 100 million parts of air. Similar calculations were made for other concentrations of ozone. The results of these calculations applying to the particular photomultiplier and filters employed in the present work are illustrated by the curves of figure 6 .

The work is simplified greatly by the fact that relative values only of the lamp energy and photomultiplier spectral response are required. Hence, amplifier and recorder sensitivities may be neglected, except to the extent that a reasonable deflection on the recorder chart should be obtained.

It is recognized that low-pressure mercury-arc lamps are affected in total and in relative spectral output by their operating temperatures. This is governed by the ambient temperature and especially

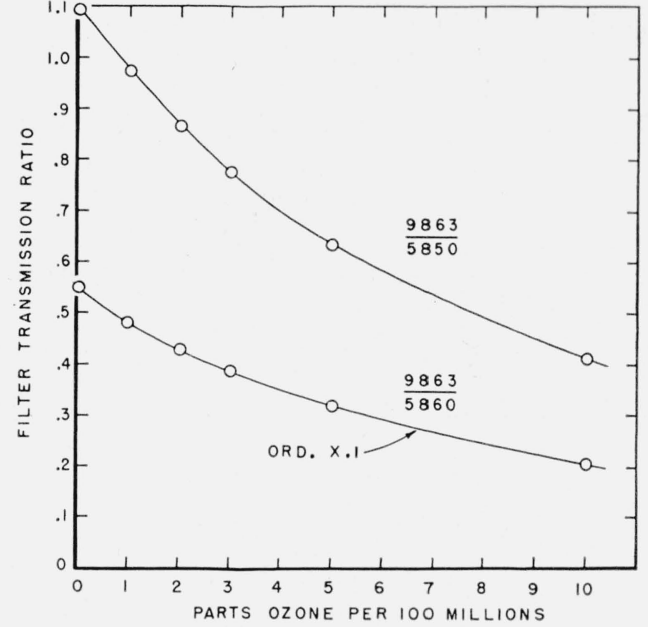

Figure 6. Calibration curves for use in translating recorder records into ozone concentrations in parts per 100 million molecules of atmosphere.

by air currents flowing past the lamp tubes. Large changes in temperature of the lamp tubes were eliminated by compactly enclosing the five lamps in a box having a small quartz-glass window through which the radiation emerged. For best results, heater units, or even temperature-control mechanisms, should be set up in the lamp box under situations of extreme temperature variation. Otherwise, the temperature may be recorded and a correction made to the calibration factor.

Selective scattering of radiation from the light by the atmosphere has been neglected in this work. Rayleigh scattering is small, and any error resulting from it is much less than that caused by other erratic changes in the atmosphere. It is assumed that any scattering by dust particles is nonselective, and therefore does not affect the transmission ratios on which the evaluation of ozone is based. In order to correct for any scattered radiation from surrounding city lights, the moon, or other sources, which might reach the photodetector, a shutter is automatically interposed in the light beam for about $1 \mathrm{~min}$ every $15 \mathrm{~min}$.

Absorption by various impurities in the atmosphere, such as smoke or other combustion or chemical vapors associated with industry or housing, produces errors of unknown magnitude. Hence, the method cannot safely be employed where any vapors having absorption in the ultraviolet spectrum (at the wavelengths of the mercury emission lines) may be intermittenly present. Many chemical and combustion vapors are known to have high ultraviolet absorption. Chimney vapors from the burning of coal, for example, when blown into the light beam cause erratic recorder tracings.

The method is not suited to daylight operation without the installation of elaborate shielding as scattered daylight, principally in the spectral region of 3,200 to $4,000 \mathrm{~A}$, will overload the $1 \mathrm{P} 28$ photomultiplier and make its modulated response nonlinear. When better filters are available, it may be 
that the response can be confined to only those wavelengths that are not in sunlight. In that case, daytime operation should be equally satisfactory.

\section{Results of Ozone Measurements at Washington, D. C.}

Over a period of several months during the late winter and early spring of 1953 an automatic record was kept of the ozone concentration over the grounds of the National Bureau of Standards for a period of about $3 \mathrm{hr}$ during the early part of each evening. Figure 7 gives an example of sections of one of these records made during an evening on which the amount of ozone varied from time to time. On most evenings there was little or no change. Except for changes associated with incoming cold air-mass fronts, no ozone concentration exceeding a few tenths of 1 part in 100 million was normally observed. Associated with these fronts, a concentration of several parts per 100 million often appeared. Sometimes the concentration of ozone fluctuated (as shown in figs. 7 and 8) or disappeared during the evening measure-

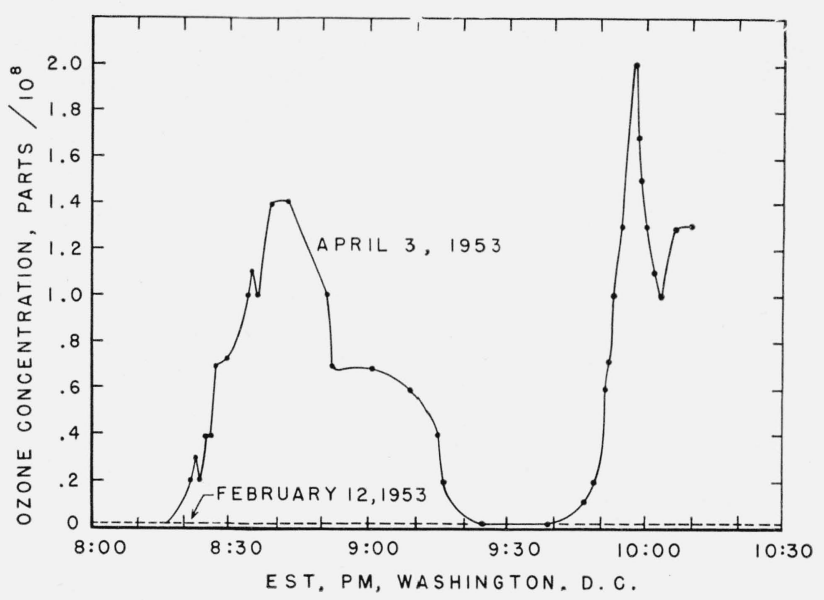

Figure 8. Variations in ozone concentration for two evenings.

February 12, 1953; mild, humid, cloudy, light northwest wind, following passage of cold front at 1:30 p. m. A pril 3, 1953; mild, sky clear, light south wind, preceding cold front and low moving in from northwest; possible upper air
instability.

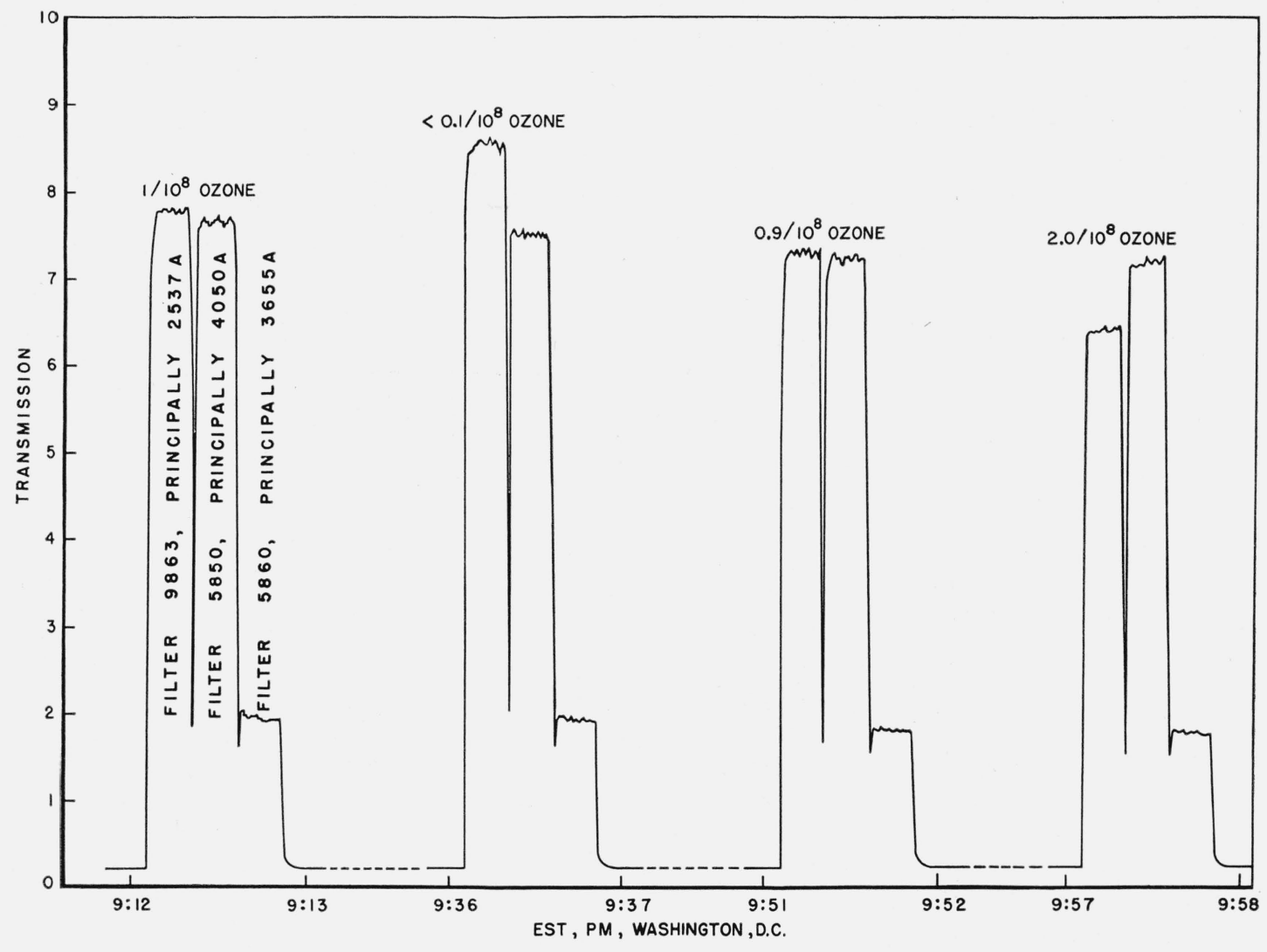

Figure 7. Sections of a recorder tracing for April 3, 1953, showing fluctuations in the ozone concentration at Washington, D. C.

The ratio of 9863 to 5850 is primarily the ratio of the transmitted intensities of 2537 A to 4050 A. Similarly, the ratio of 9863 to 5860 is primarily the ratio of the transmitted intensities of $2537 \mathrm{~A}$ to $3655 \mathrm{~A}$. 
ments. In all cases during the tests it had disappeared by the following evening.

Although the results are not conclusive, it appears that the presence of a substantial amount of ozone at Washington, D. C. is of only temporary duration. Tests with rubber samples substantiate this conclusion. No doubt the large amount of vegetation within the area is very effective in keeping ozone to a neglible value except during the short time intervals in which cold air masses are bringing it to the earth's surface within this area [15].

The high sensitivity of this equipment in the detection of ozone suggests its use in precise routine measurements at various locations in any study of the association of ozone with rubber deterioration or with possible correlations between ozone distribution and other weather phenomena.

\section{References}

[1] Gerald Bowen and Victor H. Regener, On the automatic chemical determination of atmospheric ozone, J. Geophys. Research 56, No. 3, 307 (1951).

[2] James Crabtree and A. R. Kemp, Accelerated ozone weather test for rubber, Ind. Eng. Chem., Anal. Ed. 18, 769 (1946)

[3] H. A. Winkelmann, Static exposure testing of automotive compounds, Ind. Eng. Chem. 44, 841 (1952).

[4] C. E. Bradley and A. J. Haagen-Smit, The application of rubber in the quantitative determination of ozone, Rubber Chem. and Technol. 24, 750 (1951).

[5] G. R. Cuthbertson and D. D. Dunnom, Cracking of rubber and GR-S in ozone, Rubber Chem. and Technol. 25, 878 (1952)
[6] A. W. Bartel and J. W. Temple, Ozone in Los Angeles and surrounding areas, Ind. Eng. Chem. 44, 857 (1952).

[7] A. J. Haagen-Smit, Chemistry and physiology of Los Angeles smog, Ind. Eng. Chem. 44, 1342 (1952).

[8] D. C. Thompson, R. H. Baker, and R. W. Brownlow, Ozone resistance of neoprene vulcanizates, Ind. Eng. Chem. 44, 850 (1952)

[9] Ny Tsi-Ze et Choong Shin-Piaw, L'absorption de la lumiére par l'ozone entre 3050 et 3400 A (region des bandes de Huggins), Compt. rend. 195, 309 (1932).

[10] Ny Tsi-Ze et Choong Shin-Piaw, L'absorption de la lumiére par ozone entre 3050 et 2150 A., Compt. rend. 196, 916 (1933).

[11] Ralph Stair, Photoelectric spectroradiometry and its application to the measurement of fluorescent lamps, J. Research NBS 46, 437 (1951) RP2212.

[12] S. K. Mitra, The upper atmopshere, The Asiatic Socieiy, Calcutta (1952); B. Haurwitz, The physical state of the upper atmosphere, Roy. Astron. Soc. Can., Toronto (1941); Richard Ansel Craig. The observations and photochemistry of atmospheric ozone and their meteorological significance. (Thesis, Mass. Inst. of Tech., 1948)

[13] G. M. B. Dobson, D. N. Harrison, and J. Lawrence, Proc. Roy. Soc. (London) [A] 122, 456 (1929); G. M. B. Dobson, A. W. Brewer, and B. M. Cwilong, Proc. Roy. Soc. (London) [A] 185, 144, (1946).

[14] C. F. Warburg, Z. Elektrochem. 27, 133 (1921).

[15] Herman Bogaty, Kenneth S. Campbell, and William D. Appel, The oxidation of cellulose by ozone in small concentrations, Textile Research J. 22, No. 2, 81 (1952); Alfred Ehmert, Gleichzeitige Messungen des Ozongehaltes bodennaher Luft an mehreren mit einem einfachen absoluten Verfahren, J. Atm. and Terr. Phys. 2, 189 (1952).

Washington, October 30, 1953. 